\title{
\begin{tabular}{lllll}
\hline Motrivivência & Ano XX, & No 31, P. & 143-162 & Dez./2008 \\
\hline
\end{tabular}
}

\section{Proposta Curricular para a Educação Física: uma experiência a partir da formação continuada}

\author{
Marina Ferreira de Souza Antunes? \\ Gislene Alves do Amaral2 \\ Angela Rodrigues Luiz
}

\begin{abstract}
Resumo
A atualização da prática pedagógica da Educação Física deve avançar na construção de novos argumentos que justifiquem sua presença na escola em função dos saberes escolares que Ihe são específicos, constituindoIhe uma identidade que não a subordine a outros componentes.

Por se tratar de um movimento enraizado na formação continuada, este artigo apresenta uma proposta de organização curricular que expressa a busca permanente de atualização dos processos de ensino por parte do coletivo de professores e professoras envolvidos; dentro de

Abstract

The update of the pedagogical practice of physical education should be advance the construction of new arguments to justify their presence at school on the basis of school knowledge peculiar to it, making it an identity that is not subordinate to the other components. Because it is a movement completely inside in the continuing education, this paper presents a proposal for curriculum organization that expresses the constant quest for updating of teaching by the collective of teachers and teachers involved, within a perspective of human development that overcomes
\end{abstract}

1 Professora da Faculdade de Educação Física, Universidade Federal de Uberlândia; mestre em Educação (área de concentração Educação Escolar)

2 Professora da Faculdade de Educação Física, Universidade Federal de Uberlândia; mestre em Educação: currículo, pela PUC/SP.

3 Professora da Rede Municipal de Ensino de Uberlândia, mestre em Educação. 
uma perspectiva de formação humana que supere a lógica instrumentalizada com que este componente curricular tem sido tradicionalmente tratado.

Palavras chaves: Proposta curricular; Educação Física escolar; Formação continuada

\section{Introdução}

Este artigo apresenta uma proposta de organização curricular para o ensino da Educação Física na escola, resultante de um trabalho de formação continuada desenvolvido por professores da Faculdade de Educação Física da Universidade Federal de Uberlândia, com professores da Rede Municipal de Ensino desta cidade. $\mathrm{O}$ estudo das práticas docentes como elemento central na construção e reconstrução de propostas curriculares vem ganhando fôlego em diferentes contextos, independentemente do alcance de tais iniciativas, seja em nível municipal (Recife, Juiz de Fora, Florinópolis) ou Estadual (Minas Gerais, São Paulo, Paraná, Rio Grande do Sul). Embora com diferenças, todas apontam alternativas para o tratamento dos elementos da "cultura corporal", ou "cultura corporal de movimento"4, tidos como objeto de ensino (o jogo, the instrumented with logic that this curricular component has traditionally been aborted.

Key-words: Curricular proposal;

School Phisycal Education; Continuous education

os esportes, a expressão corporal, as danças, as lutas, as ginásticas).

Conforme nos alerta Freire (1997) o momento fundamental da formação continuada está exatamente no movimento dinâmico e dialético que envolve o fazer e o pensar sobre o fazer, o instante especial em que se dá a reflexão consciente e crítica sobre a prática.

... o conhecimento fundado na reflexão das experiências é tomado como ponto de partida para o diálogo com o conhecimento já sistematizado. A relação pedagógica que se estabelece entre as partes diferencia os saberes da prática e da experiência dos saberes considerados científicos, relativamente à sua metodologia e sistematização, mas não os qualifica como melhores ou piores, ou verdadeiros ou menos verdadeiros (DALBEN, 2006, p. 137).

4 Estas expressões forma colocadas entre aspas porque, considerando que não iremos, nos limites deste trabalho, entrar no debate sobre qual delas (entre outras) deveria ser utilizada para referir-se aos conhecimentos de que trata a Educação Física na escola. 
Neste sentido, ao se optar por um tipo de metodologia que coloque em evidência o que o professor já faz, ou consegue fazer, estar-se-á procurando, ao mesmo tempo, compreender a realidade, contextualizando-a e, também, produzindo ações que possam ser desencadeadas a partir desta mesma prática, que resultem em mudanças significativas.

É justamente nesta perspectiva que procuramos enfrentar o desafio de construir, a partir do trabalho de formação continuada, um projeto político comprometido com uma concepção crítica de educação, estimulando o envolvimento e a organização coletiva de professores de Educação Física das escolas públicas e buscando minimizar algumas das dificuldades que eles mesmos identificam em seu cotidiano docente.

Este grupo de formação continuada existe desde 1996, tendo passado por diferentes momentos políticos, enfrentando as mais variadas dificuldades, sendo, portanto, fundamental destacar que o trabalho em construção é resultado de movimentos de conflitos, de lutas, de rupturas, enfim, características que, embora não possam ser aqui explicitadas, foram fundamentais para os rumos assumidos pelo grupo que persistiu até este momento envolvido com esta pro- dução. Além disso, em função do longo tempo de existência, não se pode também desconsiderar, como mais um elemento condicionante, as entradas e saídas constantes de professores no grupo, exigindo, assim, um esforço permanente para a manutenção do caráter coletivo, pela necessidade de aproximação dos que chegam e de paciência pedagógica dos antigos, permitindo, assim, que se re-criassem as condições de igualdade garantindo a participação.

O trabalho foi direcionado para construção e reconstrução de um modelo curricular que expressasse o entendimento coletivo acerca das referências estudadas, com a perspectiva de que o grupo participante se identificasse, efetivamente, como autor do processo, sendo, portanto capaz de explicar o caminho percorrido e justificar o modelo elaborado. É este modelo que pretendemos apresentar aqui, juntamente com algumas reflexões sobre os fundamentos da concepção de Educação Física que o orienta e as questões de ordem teórico-metodológica que pretende responder.

\section{O grupo de formação continu- ada: o lugar de onde falamos}

A Educação Física, desde o final da década de 1970, vem 
sendo palco de importantes debates travados na produção acadêmica, num movimento intenso de questionamentos e contestação das práticas de caráter instrumental. Neste contexto, as concepções ligadas ao desenvolvimento da aptidão física, impostas pela pedagogia tecnicista, deixaram de ser a única referência para pensar a prática pedagógica, passando a conviver com novas leituras, que trazem em suas bases contribuições da filosofia, da sociologia e de outras áreas das ciências humanas, as quais buscam construir uma outra legitimidade para a área, respondendo e justificando socialmente qual seu papel na formação dos sujeitos e na transformação da sociedade.

Este movimento na produção teórica, na medida em que vem incorporando as diferentes teorias de conhecimento, se materializa na forma de diferentes abordagens de ensino elaboradas de acordo com as perspectivas epistemológicas de seus representantes. Em que pesem as importantes contribuições destas experiências, identificamos, ao longo dos últimos 14 anos trabalhando como professoras de escolas públicas, e também na formação inicial, que a organização do trabalho pedagógico, a seleção de conteúdos e o trato com o conhecimento científico na construção do currículo continuam sendo problemas enfrentados pela área, aspectos que também são atestados por Kunz (2001). Restanos, portanto, buscar caminhos para preencher as lacunas advindas destes problemas, no sentido de estudar a realidade educacional para além da velha e sombria relação teoria e prática (Amaral, 2003).

Segundo Caparróz (2001), o tensionamento em torno da identidade da Educação Física, que resultou no chamado movimento renovador, favoreceu o surgimento de inúmeras abordagens, nomeadas segundo sua matriz teórica de origem como: Desenvolvimentista, Humanista, Construtivista, Fenomenológica, Antropológico-cultural, Histórico-crítica, Histórico-social, Sistêmica, Crítico-superadora, Crítico-emancipatória.

Dialogando também com o contexto destas produções, Castellani Filho (1998, apud Caparróz, 2001) apresenta uma proposta de organização destas abordagens a partir de uma classificação que chamou de não propositivas, propositivas sistematizadas e propositivas não sistematizadas, dando a entender que, apesar de constituírem um grande movimento na área, as abordagens apresentam, do ponto de vista da sua relação com a prática pedagógica, um diferenciador que é dado pelo seu caráter de apresentar ou não propostas de conteúdos e metodologias de ensino. 
Por outro lado, o que se pôde constatar a partir da década de 1990 em relação ao potencial destas abordagens para a transformação da prática pedagógica é o que o próprio Caparróz (2001) passou a chamar de viés prescritivo: "Não deve ser assim" indicando a necessidade de ir além da dimensão exortativa ou da prescrição por negação. Segundo ele, em função desse viés, a proposições pedagógicas não ajudaram a fundamentar a prática cotidiana; não buscaram compreender a Educação Física por aquilo que os professores fazem no cotidiano - estudaram a prática pedagógica apenas a partir dos discursos oficiais. Caparróz (2001) afirma, ainda, que a presença de um discurso opositor à racionalidade tecnocrática não foi capaz de conter o aumento do tecnicismo e da racionalidade burocrática; por fim, questiona os limites que aquelas abordagens tiveram para considerar as formas de estruturação das instituições e para decodificar as condições institucionais de escolarização.

Em Uberlândia as influências destas abordagens, ainda que de forma confusa e eclética, já estavam presentes desde 1992/93, sendo inclusive referências utilizadas em concurso público no município. Porém, tais influências também não estavam sendo convertidas em propostas que dessem conta de mudanças efetivas no cotidiano escolar e na prática social dos professores, confirmando, portanto, o hiato apontado por Caparróz (2001) entre as prescrições da produção teórica e a realidade do professor.

Se o desafio inicial era construir e implementar uma proposta curricular que estivesse fundamentada numa perspectiva crítica, seria também necessário dialogar com as diferentes leituras e níveis de compreensão acerca da realidade, e da própria produção da área, presente entre os professores. Cientes deste quadro, não foi adotado nenhum caminho preestabelecido, antes, perseguiu-se o objetivo de avançar na construção e reconstrução permanente de uma proposta curricular comprometida com a realidade da escola pública local.

Como fazer? Esta foi uma questão que não poderia ser respondida de uma vez por todas e, longe de estar totalmente satisfeita, permanece hoje na ordem do dia, uma vez que o estudo da dinâmica e complexidade do fenômeno social requer a aceitação de que toda previsão não passa de uma aproximação, limitando o conhecimento da realidade ao "campo das incertezas", no sentido de que estamos em permanente "vir a ser" individual e social.

Como foi dito na introdução deste artigo, nestes últimos anos o trabalho de formação continuada 
avançou na elaboração de um modelo curricular, resultante da revisão constante das propostas produzidas no grupo em momentos anteriores. De 2007 em diante, foram organizados quatro cursos de extensão com temáticas pensadas coletivamente em função da necessidade da continuidade do processo, de forma que o sentido do que se estava produzindo pudesse ser percebido a partir do caminho percorrido e fosse atrelado ao estudo da realidade dos professores participantes.

Ao longo deste percurso, alguns aspectos têm dificultado a implementação desta estrutura curricular, um deles é o fato de que muitos professores da rede municipal não participam deste espaço de estudo, reflexão e debate e, portanto, apresentam dificuldades em compreendê-la. Entretanto, é importante ressaltar que este distanciamento se dá por diversos fatores: alta rotatividade de professores contratados, professores que desacreditam do tipo de formação oferecida, professores que atuam em outros espaços de trabalho formal e não formal, dentre outros.

\section{O diálogo com os referenciais te- óricos: algumas aproximações}

Se aceitarmos o fato de que a realidade social será sempre muito mais complexa do que aquilo que podemos ou conseguimos dela interpretar, podemos também afirmar que nossas visões de mundo devem sempre ser consideradas provisórias, passíveis de questionamento, de ampliação ou aprofundamento, no sentido de uma busca pela aproximação e confronto entre nossas explicações ou interpretações e a realidade concreta, para superação de possíveis equívocos ou incoerências.

Neste sentido, torna-se fundamental para o desenvolvimento de um projeto pedagógico coletivo, o constante aprofundamento e/ou nivelamento teórico, desde que seja uma necessidade percebida pelo grupo a partir da sistematização da sua própria prática pedagógica. Portanto, a descrição e análise das experiências de ensino sempre se constituíram como aspecto central para direcionar os estudos, repetidas vezes, e por diferentes caminhos, sobre as teorias críticas de educação e de educação física.

A adoção deste percurso tem como pressuposto que não basta o professor "escolher" uma determinada abordagem de educação física, unicamente pela via do discurso. Antes, a incorporação de novos princípios político-pedagógicos deve ser fundamentada e refletida à luz daquilo que o professor já faz, ou sabe fazer, entendendo assim o 
planejamento do currículo como um processo permanente de análise sobre os problemas e dificuldades encontrados no cotidiano escolar.

Vale ressaltar que, em última instância, o que está proposto pelas teorias críticas de currículo é que a prática educativa seja submetida a um exame rigoroso de seu impacto na constituição dos sujeitos, dando resposta à suas implicações explícitas e/ou ocultas, de tal forma que seja possível identificar a favor de quem e contra quem se está no momento de elaborar um modelo pedagógico.

Portanto, se são muitas as perguntas que ainda temos que responder, não se deve perder de vista que a forma como estas perguntas são formuladas aponta para um determinado modo de pensar e interpretar o fenômeno educativo. Além disso, as decisões sobre o que e quando perguntar deve resultar de um diálogo do qual participam todas as vozes. A transformação da prática pressupõe aprender a elaborar boas perguntas para a realidade, para o cotidiano, para nós mesmos, para a teoria...

Arriscamos-nos a apresentar aqui algumas das questões que conduziram o grupo no estudo dos referenciais teóricos, embora não pretendamos dar respostas definitivas às mesmas, mas tratá-las de forma contextualizada e como parte constitutiva do movimento do pensamento que o grupo vem desenvolvendo em direção ao modelo curricular proposto.

1. Que concepção de existência humana deve-se tomar como referência para re-interpretar a prática pedagógica no sentido de sua transformação?

2. Que perspectiva de formação humana deve orientar o processo pedagógico?

3. Que princípios políticopedagógicos devem guiar a definição de procedimentos metodológicos?

4. Que critérios devem ser utilizados para selecionar os temas e organizar/produzir os conteúdos de ensino?

A reflexão sobre a primeira questão nos levou a identificar que a tentativa de explicar o que é o ser humano por meio da idéia dos domínios Cognitivo - capacidade de fazer uso de informações diversas por meio do pensamento (intelecto), Afetivo-social - capacidade de expressar sentimentos e emoções no nível comportamental e Psicomotor - capacidade de aprender a movimentar-se em uma escala cada vez mais complexa, é limitada e tem contribuído muito pouco para uma fundamentação crítica do fazer pedagógico. A conseqüência desta visão tem sido a fragmentação da 
existência humana expressa, inclusive, no conceito de Formação "integral" como a soma dos domínios, sendo o Domínio Cognitivo a finalidade da educação.

Ao contrário desta visão, encontramos outras formas de explicação da existência humana que tomam como referência a compreensão do que caracteriza e constitui a realidade social. Bracht (2005), citando Oliveira (1998), afirma que a corporalidade se consubstancia na prática social a partir das relações de linguagem, poder e trabalho, estruturantes da sociedade. Nesta perspectiva, a vida humana é a base para a compreensão do tipo de formação que a educação deve promover, reconhecendo aquilo que nos torna um ser social; de como devem ser nossas relações com a natureza e com a sociedade, no sentido da emancipação.

Outra interessante análise que toma também a vida concreta para pensar o ser humano e como ele se constitui pode ser encontrada em Severino (2001), segundo o qual a existência humana só se efetiva pela mediação do agir histórico-social, de tal forma que os diferentes modos de "ser humano" decorrem das diferentes formas de agir constituídas historicamente, sendo, portanto, a prática a essência deste existir.
O existir é, antes de tudo desdobrar-se pelo agir numa interação permanente e intensa com os dados da natureza material, com os outros sujeitos na sociedade e com as construções simbólicas, subjetivamente produzidas por sua consciência e guardadas na memória e objetivamente conservadas pela cultura (SEVERINO, 2001, p. 44).

A compreensão de como se configura a existência humana, na perspectiva deste autor, se completa com a introdução do conceito de tridimensionalidade. As raízes desta leitura podem ser encontradas, do ponto de vista filosófico, na explicação materialista sobre a origem da consciência humana como dimensão da subjetividade que

(...) emerge como uma função plenamente integrada aos processos das atividades que os homens passaram a desenvolver para cuidar da própria sobrevivência material. (...) É por isso também que pensamento e ação se misturam e se vinculam em suas origens (SEVERINO, 1994, p. 33).

Em seu percurso de relações mediadas, o homem vai se constituindo e conservando sua existência concreta na medida em que se relaciona com a natureza 
(prática produtiva - trabalho) com os outros (prática política - poder) e com seu próprio modo de pensar (prática simbólica - linguagem).

Neste sentido a concepção de formação humana (segunda questão) deve pautar-se: no reconhecimento do processo simbólico de representação da realidade, seja ela verbal ou não-verbal, por meio de uma racionalidade cuja materialização pressupõe relações intencionais e, portanto, devem ser aprendidas; na identificação da dimensão produtiva da existência, que resulta em conhecimento de caráter técnico-normativo; no conhecimento dos mecanismos que regulam a vida social, ou seja, as relações políticas estabelecidas a partir de interesses (troca por lucro/ busca consenso).

Sustentando ainda as reflexões sobre a formação humana, avançando para a terceira questão entendemos, segundo Rocha (2000), que, do ponto de vista da perspectiva histórico-cultural, o desenvolvimento humano ou "movimento de humanização" não pode ser explicado pelo viés da atualização de capacidades dependentes apenas do aspecto maturacional e nem de aquisições acumulativas que se ampliam de forma gradual e linear. $\mathrm{O}$ desenvolvimento precisa ser compreendido na relação com as condições concretas de vida, que se organizam segundo as particularidades culturais e históricas dos sujeitos.

Neste contexto de análise, a autora apresenta o conceito de mediação, como categoria fundamental que permite entender como se dá "a apropriação do mundo pelos sujeitos em suas relações e a emergência de processos psicológicos internos" (ROCHA, 2000, p. 31). Humanização, portanto, é o movimento dialético de produção da vida cultural em suas diferentes manifestações e se dá por meio de três formas de mediações interconectadas: a instrumental, a semiótica e a social:

A mediação instrumental refere-se à utilização de apoios externos pelo homem para agir no mundo; a mediação semiótica referese à linguagem, que é o sistema de signos, através dos quais se transmite o conhecimento produzido pela humanidade (sendo, portanto um instrumento) e ao mesmo tempo é instancia fundamental para a compreensão das relações humanas (mediação social); a mediação social refere-se à participação do outro e opera por duas formas: a atividade conjunta com objetos (mediação instrumental) e a comunicação por meio da linguagem (mediação semiótica)

Rocha (2000) dialoga também o conceito vigotskiano de Zona de Desenvolvimento Proximal, 
resultado de experiências compartiIhadas entre o sujeito que ainda não é capaz de realizar determinadas atividades sozinhas, com sujeitos mais experientes
A Zona de Desenvolvimento proximal é, portanto, o encon- tro do individual com o social, de que retoma a concepção de desenvolvimento não como processo interno da criança, mas como processo resultante da sua (da criança) inserção em atividades socialmente compar- tilhadas com outros (ROCHA, 2000, p. 40).

Neste processo, as mudanças acontecem como resultado de relações inter (entre sujeitos) e intrapsicológicas (singulares), sendo, assim, internalizadas. Daqui se depreende a idéia de que "aprender" e "desenvolver" podem ser considerados processos dinâmicos de internalização da cultura, que se relacionam ao longo de toda a vida. Nesta relação, que é dialética, a aprendizagem possibilita desenvolvimento, que por sua vez permite aprendizagens novas e diferenciadas. Entretanto, este processo não é natural ou espontâneo, nem pode ser explicado por leis causais, sendo esta compreensão fundamental para repensarmos a nossa prática pedagógica.
O ato de ensinar é, portanto, uma forma de mediação (chamada por Rocha de mediação pedagógica), que, do ponto de vista do desenvolvimento humano, se contrapõe à perspectiva psicologicista que serviu de base para a construção de justificativas que supunham uma possível "integração" destes domínios, a partir de uma lógica de interdependência entre eles. Entretanto, se tomarmos o conceito de mediações em Rocha (2000), entendemos que podemos avançar na compreensão da indissociabilidade entre as dimensões instrumental, semiótica e social, na medida em que interpretamos cada uma delas como sendo processos interligados que se efetivam a partir e no contexto histórico-cultural. Por este motivo, nos referimos à formação humana como sendo resultado de aquisição/ internalização de conhecimento de natureza instrumental, social e comunicativa, ao que chamamos formação humana ampliada.

Portanto, a organização do processo pedagógico e a definição de procedimentos metodológicos deverão favorecer os saltos qualitativos do aluno em sua trajetória escolar. Neste caminho, conseguimos estabelecer alguns consensos acerca dos seguintes elementos do planejamento: processo pedagógico: consiste na identificação do caminho do pensamento que 
possibilita a aquisição/construção do conhecimento pelos alunos tendo como base o projeto curricular (perspectiva dialética: síncrese análise - síntese); procedimentos metodológicos: são ações que o professor irá adotar para tornar significativo o processo metodológico, podendo, portanto variar de acordo com o desenvolvimento da turma, as condições materiais da escola, dentre outros aspectos.

Na discussão sobre a produção de saberes escolares e sua organização no currículo ao longo do processo de escolarização, partimos da pergunta: $\mathrm{O}$ que a educação física ensina?, buscamos identificar os aspectos que caracterizam a especificidade de nosso objeto de ensino na escola, com a finalidade de ampliar o olhar sobre esta questão, auxiliando-nos na revisão do modelo curricular.

Por meio de uma chuva de idéias identificamos quais eram, para o grupo, os elementos constitutivos que caracterizam o ensino da educação física na escola. Um primeiro diálogo, nesse momento, se deu com Bracht (2005), onde aponta a perspectiva de se utilizar a categoria cultura para referir-se àquilo que caracteriza o objeto de ensino do componente curricular educação física. Destacamos aqui a necessidade de entendermos práticas corporais como construções históricas, o que significa estudálas a partir de reflexões advindas das ciências sociais e humanas, compreendendo os sentidos e significadas a elas atribuídos nos contextos culturais em que foram/ são produzidas.

Nesta mesma direção, dialogamos também com Aranha (1996) e sua explicação sobre o processo de produção da cultura como resultado de relações que o homem estabelece com a natureza e consigo si mesmo (relações de trabalho, relações políticas e relações culturais/comunicativas). O conceito de cultura, segundo ela se distingue da idéia de "acesso à instrução/erudição", expressando, por um lado, o resultado de tudo o que o homem produz para construir sua existência, e por outro o conjunto de representações simbólicas, por meio do qual os homens se comunicam de forma cada vez mais elaborada e que permite tanto a produção quanto a conservação da cultura.

A partir deste conceito, a autora evidencia os aspectos que diferenciam as ações humanas das atividades dos animais. No segundo caso, as ações são determinadas pelas condições biológicas, que Ihes permitem adaptar-se ao meio em que vivem, não sendo livres para agir em discrepância com sua natureza. Por esta razão não tem 
história, não dominam o tempo, porque seu ato se esgota no momento em que o executa.

O homem, ao contrário, é capaz de agir sobre a natureza e sobre si mesmo, por meio da atividade chamada trabalho. Neste processo pode reproduzir atividades de outros homens e inventar novas, tomando sua própria ação como fonte de idéias - a isto Aranha (1996) chama de "experiência humana".

As relações que os homens estabelecem entre si para produzir a cultura se dão em diversos níveis que não se excluem, mas se complementam e se interpenetram. Apenas por questões didáticas costumamos separar e distinguir essas relações em: relações de trabalho, (...) relações políticas, (...) e relações culturais (...) (p. 17).

Tomando a cultura como fonte e substrato tanto para a compreensão quanto para produção do conhecimento, podemos afirmar que as práticas corporais devem constituir-se como fenômenos a serem estudados pelo componente curricular Educação Física, com a finalidade de identificar o conhecimento necessário para uma apropriação crítica das mesmas do ponto de vista das possibilidades de sua vivência no tempo de lazer, dos sentidos e significados culturalmente a elas atribuídos e das condições concretas de sua organização no contexto social.

Estas reflexões, na medida em que dialogam com a prática pedagógica, na formação continuada, tem nos conduzido a um movimento constante de formular novas perguntas que, por sua vez, exigem novos estudos, permitindo o "retorno" à prática pedagógica, num processo de realimentação do currículo.

Portanto, o que apresentamos como proposta para a Educação Física resulta, não de uma apropriação linear da teoria ou, de uma possível "aplicação" da mesma, mas do que tem sido possível desenvolver por meio do confronto com a realidade. Por este motivo, é necessário reafirmar o entendimento de que

[...] o professor não deve aplicar teoria na prática, e sim, (re) construir (reinventar) sua prática com referência em ações/ experiências e em reflexões/ teorias. É fundamental que esta apropriação de teorias se dê de forma autônoma e crítica, portanto, como ação de um sujeito, de um autor (CAPARROZ \& BRACHT, 2007, p. 27).

A constante revisão dos referenciais teóricos nos permite 
chegar a momentos de síntese, como este, nos quais a prática pedagógica indica as contribuições da teoria, para sua compreensão e/ou transformação, e não o contrário. Além disso, estas reflexões devem conduzir a compreensão de como o conhecimento deve ser organizado, na forma de saberes escolares produzidos de forma autônoma e não copiados ou reproduzidos a partir de currículos impostos ou programas prontos.

$\mathrm{Na}$ medida em que compreendemos que o movimento/exercício do pensamento não é linear e que dele depende nossa capacidade de descrever, explicar, problematizar e transformar a realidade (neste caso a prática pedagógica), não podemos mais abrir mão de uma apropriação crítica e reflexiva do conhecimento produzido sobre nosso objeto de ensino. Esta atitude implica, num primeiro momento, reconhecer os limites da formação técnico-instrumental a que fomos submetidos, a qual nos impôs uma ação educativa reduzida a mera reprodução das práticas corporais hegemonicamente aceitas como válidas.

E num segundo momento, implica também assumirmos a disposição de aprender aquilo que desconhecemos, ou conhecemos superficialmente, em especial, o conhecimento advindo das ciências humanas e sociais (história, sociologia, antropologia, filosofia), muitas vezes negado ou rejeitado em função, dentre outros aspectos, da lógica fragmentada com que tradicionalmente foi tratada a relação teoria e prática. É por este motivo que temos insistido na prática da problematização, do questionamento aos conhecimentos cristalizados em nosso imaginário, na medida em que consideramos ser este um passo fundamental para aprendermos a estudar a realidade, elaborando sempre novas perguntas que poderão indicar por onde teremos que caminhar na construção de nossa autonomia científica, política e pedagógica.

\section{Apresentação de um modelo curricular para a Educação Física}

Como preâmbulo para apresentação desta proposta, é importante chamar atenção para o fato de que, para nós, o estabelecimento de uma forma de pensar a estrutura curricular é o que, de certa forma, permite uma visualização da materialidade do componente curricular, conferindo-lhe identidade e expressando seu sentido no processo de escolarização.

Já é antigo o debate sobre a especificidade da Educação Física em termos do seu conhecimento e dos conseqüentes conteúdos de 
ensino. As discussões no grupo de formação continuada nos levaram a rever alguns aspectos deste debate, pois identificamos a presença de uma linguagem ainda muito controvertida em relação aos termos que se utiliza para dizer o que cada elemento significa no modelo curricular, em função, principalmente, do nível diferenciado que cada participante se encontra, alguns estão desde 1996 no grupo, outros são recém contratados e outros já não participam mais. Entretanto, observamos que o debate acadêmico expresso nas produções da área e que tem sido problematizado em diversos artigos publicados nos periódicos, também tratam a questão dos conteúdos de ensino de formas diferenciadas (BRACTH, 1996; SOARES, 1996; OLIVEIRA, 1999).

A elaboração da estrutura curricular não se caracterizou como uma mera escolha de termos "adequados", mas sim num processo de ressignificação dos temas e conteúdos, uma vez que, a terminologia utilizada deve refletir os conceitos que nos orientam na elaboração do modelo. Optamos, portanto pela organização de três elementos: Eixos Temáticos, Temas de Ensino e Conteúdos de Ensino.

Eixos Temáticos passaram a significar para nós, determinados contextos da vida social, cujas práticas sociais, ali agrupadas, implicam a incorporação de conhecimentos advindos de diversas áreas, representando campos de conhecimento que agrupam produções culturais que podem ser identificadas como o objeto de ensino na Educação Física Escolar.

Eixo 1 - Educação Física tem a Escola e a Educação Física como temas a serem abordados da educação infantil ao $9^{\circ}$ ano do ensino fundamental. Deve apreciar tanto conhecimentos sobre a instituição escola quanto do componente curricular educação física no cenário da educação formal em nossa sociedade, apontando e justificando a educação física como conhecimento a ser ensinado na escola, bem como a contribuição da escola e da educação física no processo de formação humana, cooperando em primeira instância para a justificativa e valorização desta última, no contexto escolar;

Eixo 2- Manifestações Corporais compreende o estudo sobre as manifestações corporais tradicionalmente atribuídas como objeto a ser ensinado na escola pela disciplina Educação Física, cujos elementos constitutivos são reconhecidos socialmente e estão inseridas na realidade a partir de características comuns como: possuir gestos e técnicas próprias, regras, locais, vestuários, equipamentos pré-definidos. Busca a identificação, 
experimentação e reflexão sobre estas manifestações, com a finalidade de compreender suas relações com os aspectos históricos, políticos e com a formação humana, apontando a possibilidade de elaboração, reconstrução e permanente reinvenção das mesmas de maneira crítica e coletiva;

Eixo 3- Corporeidade Humana contempla o conhecimento sobre o corpo, em suas diferentes dimensões, como elemento constitutivo da existência humana, relacionando os estudos existentes sobre a concepção da corporeidade humana com o agir social, levando em conta os modismos e influências da mídia na construção de uma visão de corpo nos contextos histórico-culturais. Os temas de ensino, neste eixo, devem tratar o corpo a partir de uma perspectiva estética, histórica e social, para além do conhecimento biológico, com a finalidade de romper com a visão fragmentada "corpo-mente" que, historicamente, predominou na área da educação física;

Eixo 4- Lazer na educação física escolar deve contemplar o estudo sobre as manifestações corporais que podem ser materializadas no tempo do não trabalho. Abordando aspectos do conhecimento que permitam compreender as implicações do desenvolvimento tecnológico no campo do lazer, as diferentes possibilidades de práticas de lazer, identificando os locais e equipamentos de lazer, bem como a relação entre o público e o privado no âmbito do lazer como direito social. A discussão sobre estes temas deve nos remeter também ao estudo das diferentes práticas sociais levando em consideração os aspectos políticos, sociais, econômicos e da formação humana;

Eixo 5- Atividade Física/ Qualidade de Vida se caracteriza pelo estudo da Atividade Física em suas diferentes possibilidades e limites de materialização na vida social, compreendendo-a como uma construção histórica que se fundamenta no conhecimento advindo das ciências naturais, atendendo a interesses políticos, sociais e econômicos. Considera-se, ainda, para a reflexão neste eixo, as múltiplas relações entre Atividade Física e Qualidade de Vida, nos remetendo ao campo da Saúde, especialmente pela visão tradicionalmente presente neste, de uma possível relação de causa e efeito entre ambas. Neste sentido, torna-se fundamental que, na escola, os alunos sejam conduzidos à uma compreensão dos aspectos que definem Qualidade de Vida em diferentes contextos histórico-culturais e sócio-econômicos, pois trata-se de um conceito que deve ser justificado por critérios definidos a partir das condições concretas da vida social.. 
Os Temas de Ensino são as diferentes atividades humanas que podem e devem ser reconhecidas, compreendidas e problematizadas nas aulas de Educação Física, de acordo com a concepção de educação que nos orienta, sendo, portanto, agrupadas em Eixos Temáticos, expressando, assim, a leitura da realidade, justificada com base no projeto político pedagógico da área. Na atual estrutura curricular são apresentados os seguintes temas de ensino, distribuídos nos eixos temáticos: Educação Física: A Escola e A educação Física como componente curricular; Manifestações Corporais: Esporte, Jogos, Ginástica, Danças, Lutas, Brincadeiras de Rua, Teatro, Capoeira, Circo e Jogos Olímpicos; Corporeidade Humana: Órgãos dos sentidos, Produção Midiática, Mundo do Fitness, Corpo e Indústria da Moda; Lazer: Racha/ pelada, Ruas de Lazer, Colônia de Férias, Jogos Eletrônicos, Atividades de "aventura" e Políticas públicas do lazer; Atividade Física e Qualidade de Vida: Alimentação, Aspectos biológicos, Exercício Físico, Patologias associadas ao exercício físico e Fisioterapia desportiva.

Vale ressaltar que a organização dos temas não é estática, permitindo sua mobilidade entre os eixos, dependendo dos objetivos de ensino, sendo possível, também a criação de novos temas advindos da realidade cultural. Além disso, os aspectos atribuídos aos Conteúdos de Ensino são comuns aos diversos Temas, pois apontam o tratamento que pode ser dado ao conhecimento acerca dos mesmos.

Os Conteúdos de Ensino são aspectos do conhecimento sobre cada tema, tomados como referência para a produção de saberes escolares, os quais podem contribuir para uma compreensão crítica acerca da realidade social. Sua compreensão passou a ser entendida na lógica da produção de saberes escolares, sendo um processo que ocorre antes durante e depois do ato de ensinar, do qual participam professores e alunos. Para orientar organização do conhecimento por meio dos conteúdos foram definidos cinco aspectos: 1- Elementos constitutivos - descrição dos fenômenos a partir da identificação de sua materialização na realidade concreta (aparência), visando reconhecer o que, como, quem e onde; 2- Classificaçãocaracterização - agrupamento dos elementos da cultura tomados como objeto de estudo-ensino a partir de critérios previamente definidos, de forma a identificar os aspectos que permitem saltos qualitativos na forma de explicá-los, dependendo dos objetivos de estudo; 2- Conceitualização - processo de organização do pensamento para a produção de 
novas sínteses teóricas, avançando para uma compreensão mais aprofundada da realidade; 4- Contextualização sócio política - a relação dos temas estudados com o modelo de sociedade, as formas de interação humana e as relações de poder e 5- Institucionalização - processo por meio do qual as práticas sociais são organizadas e reorganizadas na sociedade, por meio de diferentes modelos institucionais, permeados de interesses sociais, econômicos e políticos.

O diálogo que nos permitiu avançar na explicação desta estrutura curricular se deu com Saviani (1998), especificamente na discussão que ela faz das relações entre conteúdo e método de ensino. Esta relação é abordada pela autora a partir de sua aproximação com a relação currículo-didática, implicando numa compreensão dos processos de produção dos saberes escolares, e sua organização numa matriz curricular; e do processo de escolarização por meio do qual a trajetória pedagógica é desenhada à luz de uma visão sobre o desenvolvimento do aluno. Segundo ela

[...] o conteúdo do processo pedagógico refere-se, fundamentalmente, ao conjunto de conhecimentos e técnicas cuja assimilação/apropriação a escola deve propiciar aos edu- candos; e o método refere-se à necessária trajetória a ser percorrida para que isto seja garantido (SAVIANI, 1998, p. 10).

Entendemos que as discussões sobre a organização curricular devem resultar de uma permanente reflexão sobre a realidade escolar, sistematizada nos estudos realizados na formação continuada, visando sua reformulação sempre que avanços teórico-práticos são alcançados. Vale destacar que neste processo permanente de busca de alternativas curriculares, é fundamental reconhecer a autoria dos professores e sua autonomia político-pedagógica na produção do currículo; ter clareza, tanto da função docente, quanto do que deve ser ensinado e do sentido e significado de se aprender determinada prática social para a formação do aluno.

O quadro abaixo apresenta um exemplo da apropriação desta organização curricular para o planejamento do ensino, explicitando a concepção resultante da produção coletiva na formação continuada e que vem sendo utilizada para a elaboração do planejamento no cotidiano das escolas da Educação Básica. Este quadro é parte de um documento que denominamos plano anual e que a cada ano passa por reformulações, incorporando os 
avanços coletivos ${ }^{5}$. O Plano Anual materializa um esforço coletivo de distribuição dos Temas de Ensino ao longo do processo de escolarização oferecido na Rede municipal (Ed. Infantil e Ensino Fundamental). Ainda que tenhamos avançado em alguns aspectos na produção do currículo, é preciso reconhecer que os quadros elaborados pelos grupos de trabalho não estão prontos e devem ser tomados como uma versão provisória desta nova organização curricular.

\begin{tabular}{|c|c|c|c|c|}
\hline Zona & $\begin{array}{l}\text { Eixo } \\
\text { Temático }\end{array}$ & Tema de Ensino & Conteúdo de Ensino & Recursos metodológicos \\
\hline $\begin{array}{l}\text { Ed. } \\
\text { Infantil }\end{array}$ & $\begin{array}{l}\text { Manifestações } \\
\text { Corporais }\end{array}$ & Brincadeiras/jogos & $\begin{array}{l}\text { Conceitualização: Introdução ao } \\
\text { conceito de jogo tradicional a } \\
\text { partir da identificação de seus } \\
\text { elementos constitutivos }\end{array}$ & $\begin{array}{l}\text { Conceituar a partir da } \\
\text { experiência da criança. } \\
\text { reproduzir espaço físico, } \\
\text { materiais e regras de } \\
\text { brincadeiras tradicionais; } \\
\text { jogos de cooperação e } \\
\text { integração, ginásticos, } \\
\text { brincadeiras e jogos } \\
\text { cantados, expressão } \\
\text { corporal através da } \\
\text { música e da dança. }\end{array}$ \\
\hline $\begin{array}{l}\text { Ed. } \\
\text { Infantil }\end{array}$ & $\begin{array}{l}\text { Manifestações } \\
\text { Corporais }\end{array}$ & $\begin{array}{l}\text { Dança (dança } \\
\text { junina) }\end{array}$ & $\begin{array}{l}\text { Elementos Constitutivos } \\
\text { (da dança junina: ritmo, } \\
\text { passos,coreografias,vestuário...) } \\
\text { Contextualização Sócio Politica } \\
\text { (a dança junina como elemento } \\
\text { da cultura popular e sua relação } \\
\text { com as tradições culturais) }\end{array}$ & $\begin{array}{l}\text { Apresentação da origem } \\
\text { da festa junina. } \\
\text { Sensibilização rítmica. } \\
\text { Reprodução coreográfica } \\
\text { de uma } \\
\text { dança junina. }\end{array}$ \\
\hline $\begin{array}{l}\text { Ed. } \\
\text { Infantil }\end{array}$ & $\begin{array}{l}\text { Corporeidade } \\
\text { Humana }\end{array}$ & $\begin{array}{l}\text { Corpo, Midia e } \\
\text { induistria da moda }\end{array}$ & $\begin{array}{l}\text { Elementos Constitutivos } \\
\text { (veículos de propaganda, a TV, o } \\
\text { rádio, o jornal, vestuário, o } \\
\text { corpo, o belo, o feio) }\end{array}$ & $\begin{array}{l}\text { História em quadrinhos. } \\
\text { Recorte de gravuras. } \\
\text { Entrevista com membros } \\
\text { da familia ou amigos ( } 6 \\
\text { anos) }\end{array}$ \\
\hline
\end{tabular}

5 Desde o ano de 2000 o grupo de formação continuada tem feito um esforço para elaborar um documento, que a partir do processo vivenciado durante o ano, oriente a prática pedagógica dos professores. No entanto reproduzir toda esta materialização não foi possível, pelo limite de espaço deste artigo, por isso colocamos esta sistematização a título de exemplo daquilo que vimos produzindo com os professores. 


\section{Referências}

AMARAL, G. A. do. Planejamento de Currículo na Educação Física: possibilidades de um projeto coletivo para as escolas públicas de Uberlândia/MG. Dissertação. São Paulo: PUC, 2003.

ARANHA, M. L. de A. Filosofia da Educação. São Paulo: Moderna, 1996.

BRACHT, V. Educação Física no $1^{\circ}$ grau: conhecimento e especificidade. Revista Paulista de Educação Física. Suplemento n.2, 1996, p.23-28.

BRACHT, V. Cultura Corporal, Cultura de Movimento ou Cultura Corporal de Movimento? In: SOUZA JÚNIOR, M. B. M. (Org.) et al Educação Física Escolar: teoria e política curricular, saberes escolares e proposta pedagógica. Recife: EDUPE, 2005, v. 1, p. 96-106.

CAPARROZ, F. E. Discurso e prática pedagógica: elementos para a compreensão da complexa teia que envolve a educação física na dinâmica escolar. In: CAPARROZ, F. E (Org.) Educação Física Escolar: política, investigação e intervenção. Vitória: Proteoria, 2001, vol. 1, p.193-214.

CAPARROZ, F. E. \& BRACHT, V. O tempo e o lugar de uma didática da educação física.
Revista Brasileira de Ciências do Esporte, Campinas, v.28, n.2, jan. 2007. p. 21-38.

DALBEN, A. I. L. de F. Formação continuada de professores: idéias para a construção de uma política integrada entre universidade e sistema de ensino. IN: CALDERANO, M. da A. \& LOPES, P. R. C. Org. Formação de professores no mundo contemporâneo: desafios, expectativas e perspectivas. Juiz de Fora. EDUFJF, 2006, p. 131-146.

FREIRE, P. Pedagogia da autonomia. São Paulo: Cortez, 1997.

KUNZ, E. Fundamentos normativos para as mudanças no pensamento pedagógico em educação física no Brasil. In: CAPARROZ, F. E (Org.) Educação Física Escolar: política, investigação e intervenção. Vitória: Proteoria, 2001, vol. 1, p. 9 - 38.

OLIVEIRA, M. A. T. Existe espaço para o ensino da Educação Física na Educação Básica. Pensar a Prática 2, 1998/1999. p. 119135.

ROCHA, M. S. P. de M. L. da. Não brinco mais: a (des)construção do brincar no cotidiano educacional. ljuí, Unijuí, 2000.

SAVIANI, N. Saber escolar, currículo e didática: problemas da unidade conteúdo/método no processo pedagógico. 2ed. 
Campinas: Autores Associados, 1998.

SEVERINO, A. J. Filosofia. São

Paulo: Cortez, 1994. . Educação, sujeito e

história. São Paulo: Olho d' Água, 2001.

SOARES, C. L. Educação Física

Escolar: conhecimento e especificidade. Revista Paulista de Educação Física, Suplemento n.2, 1996. p.6-12.
Recebido: 17/fevereiro/2010.

Aprovado: 22/abril/2010. 